\title{
The role of Probiotics in allergic diseases
} Sonia Michail

Address: Department of Gastroenterology and Nutrition, Wright State University Boonshoft School of Medicine Dayton Children's Medical Center, Dayton, Ohio 45404, USA

Email: Sonia Michail - sonia.michail@wright.edu

Published: 22 October 2009

Allergy, Asthma \& Clinical Immunology 2009, 5:5 doi:10.1 186/1710-1492-5-5

This article is available from: http://www.aacijournal.com/content/5/I/5

(C) 2009 Michail; licensee BioMed Central Ltd.

This is an Open Access article distributed under the terms of the Creative Commons Attribution License (http://creativecommons.org/licenses/by/2.0), which permits unrestricted use, distribution, and reproduction in any medium, provided the original work is properly cited.
Received: I October 2009

Accepted: 22 October 2009

\begin{abstract}
Allergic disorders are very common in the pediatric age group. While the exact etiology is unclear, evidence is mounting to incriminate environmental factors and an aberrant gut microbiota with a shift of the ThI/Th2 balance towards a Th2 response. Probiotics have been shown to modulate the immune system back to a ThI response. Several in vitro studies suggest a role for probiotics in treating allergic disorders. Human trials demonstrate a limited benefit for the use of probiotics in atopic dermatitis in a preventive as well as a therapeutic capacity. Data supporting their use in allergic rhinitis are less robust. Currently, there is no role for probiotic therapy in the treatment of bronchial asthma. Future studies will be critical in determining the exact role of probiotics in allergic disorders.
\end{abstract}

\section{Introduction}

Currently, an estimated $20 \%$ of the population worldwide is suffering from some form of allergic disorder with a prevalence that continues to rise [1]. For example, the prevalence of childhood asthma in the USA increased by $50 \%$ from 1980 to 2000 [2]. Atopic diseases involve Th2 responses to allergens [3]. These clinical disorders are characterized by immediate hypersensitivity.

Although the exact etiology of allergic diseases remains ambiguous, many investigators have proposed that environmental exposures may be major trigger factors in the development of allergic diseases. As the rise in prevalence of allergic diseases has been seen mostly in industrialized countries, this led investigators to formulate the hygiene hypothesis in an attempt to explain the basis of the disease. This hypothesis entails that reduced family size and childhood infections have lowered our exposure to microbes, which play a crucial role in the maturation of the host immune system during the first years of life[4].
In addition to environmental factors, the intestinal flora may be a contributor to allergic disease due to its substantial effect on mucosal immunity. Allergic responses are thought to arise if there is absence of microbial exposure while the immune system is still developing [5,6]. Exposure to microbial flora early in life allows for a change in the Th1/Th2 balance, favoring a Th1 cell response. Several reports suggest that the make-up of intestinal microflora can be different in individuals with allergic disorders and in those who reside in industrialized countries where the prevalence of allergy is higher [7-9]. For example, children from an industrialized country like Sweden harbor less Lactobacilli and Bifidobacteria (and more Staphylococcus aureus and Clostridia) in their bowels in comparison to children who live in countries like Estonia where allergic disorders are not as common [10-12].

The concept that children with allergic disorder harbor a different profile of microflora has been supported by several other studies [8,13-17]. Perhaps the most convincing 
of these is the KOALA study, which examined flora of 957 infants in the Netherlands [18]. The study revealed that $C$. dificile colonization at one month of age was associated with an increased likelihood of eczema, recurrent wheezing, and atopic dermatitis. E. coli colonization was associated with eczema rather than recurrent wheezing or atopic dermatitis. No association with bifidobacteria colonization, B. fragilis or lactobacilli colonization was observed.

While this concept has been validated in several other studies, there are a few reports that do not show a significant difference in microflora composition. A recent study comparing microflora composition of 324 European infants showed no association between food sensitization or atopic dermatitis and the intestinal bacteria [19]. In general, however, most studies suggest that an association exists.

\section{Mechanisms of action of probiotics in allergic disorders}

The United Nations Food and Agricultural Organization and the World Health Organization define probiotics as "live microorganisms, which, when administered in adequate amounts, confer a health benefit to the host" [20]. Prebiotics are defined as non-digestible oligosaccharides, such as fructo-oligosaccharides and trans-beta-galacto-oligosaccharides, that selectively stimulate the growth of bifidobacteria and lactobacilli, thus producing a prebiotic effect. Synbiotics is a term referring to the use of both prebiotics and probiotics simultaneously.

As described above, allergic disorders are associated with a shift of the Th1/Th2 cytokine balance towards a Th2 response. This leads to activation of Th2 cytokines and the release of interleukin-4 (IL-4), IL-5, and IL-13 as well as IgE production [21].

Probiotics can potentially modulate the toll-like receptors and the proteoglycan recognition proteins of enterocytes, leading to activation of dendritic cells and a Th1 response. The resulting stimulation of Th1 cytokines can suppress Th2 responses [21]. Pediatric studies suggest that probiotic use in children with atopic conditions such as atopic dermatitis results in enhancement of IFN-production and decrease $\mathrm{d}$ IgE and antigen-induced TN F-, IL-5, and IL-10 secretion [22-24].

\section{The role of probiotics in allergic disorders}

The interest in probiotic therapeutic potential in allergic disorders stemmed from the fact that they have been shown to reduce inflammatory cytokines and improve intestinal permeability in vitro. Such effects would be desirable in treating allergic disorders. Therefore, several studies have been designed to examine the efficacy of probiotics in many allergic conditions, such as eczema, allergic rhinitis, asthma and food allergies.

\section{a) Role of probiotics in atopic dermatitis}

Several human trials, as well as, numerous animal and in vitro studies suggest a beneficial effect of probiotics in allergic diseases. The therapeutic and preventive role of probiotics in atopic dermatitis has been extensively studied.

\section{Prevention of atopic dermatitis}

The prevention of allergic diseases relies heavily on preventing sensitization to an offending allergen. Enomoto and colleagues investigated the association of consumption of fermented dairy products and the development of allergy and allergic sensitization in Japanese students as reflected on serum levels of total IgE values, specific IgE to house dust mite and Japanese cedar pollen. The report demonstrated a significant reduction in allergy development among the students consuming fermented milk in comparison with students who did not consume fermented products[25].

The effect of probiotics on preventing atopic dermatitis has been demonstrated in randomized studies from Finland where Lactobacillus GG or placebo was given to pregnant mothers with a strong family history of eczema, allergic rhinitis or asthma, and to their infants for the first six months after delivery. The frequency of developing atopic dermatitis in the offspring was significantly reduced by 2,4 , and 7 years [26-28], by $50 \%, 44 \%$, and $36 \%$ respectively.

Similar studies have yielded comparable results. The use of the probiotic E-coli in the early postnatal period decreased the incidence of serum specific IgE allergies at 10 and 20 years of age in a long-term prospective study $[29,30]$. Other studies could only relate probiotic benefits to a certain subset of dermatitis patients. The incidence of IgE-associated dermatitis, rather than other types of atopic dermatitis, was decreased after the oral consumption of probiotics, namely $L$. reuteri or a mixture of four probiotic bacteria and prebiotics [31,32]. However, Taylor et al could not confirm such effects in a randomized placebocontrolled double-blind study. L. acidophilus did not decrease the risk of developing allergy in a large number of infants[33,34]. There were two major differences between Taylor ${ }^{\mathrm{D}} \mathrm{s}$ study and the others. The type of probiotic product was different as well as the timing of the introduction of the probiotic, Taylor et al administered the probiotic supplement postnatally, while other studies administered probiotics before and after birth. Prenatal supplementation may prove to be crucial for the preventive benefit of probiotics in this disorder.

Prebiotic oligosaccharides have also been shown to reduce the incidence of atopic dermatitis when given to infants at risk for atopy during the first six months of 
age[35]. No comparisons made to probiotics and have not been used prenatally.

A recent Cochrane review meta-analysis found a significant reduction in the likelihood of developing infant eczema with the use of probiotics. The meta-analysis described five studies enrolling 1477 infants. However, the authors found significant heterogeneity and with further focused on children with dermatitis that have positive skin prick test or specific IgE sensitization, there were no significant benefits noted with probiotics. The authors concluded that there was no current evidence to support the administration of probiotics to prevent eczema and recommended further studies to determine reproducibility[36].

In general, the role for probiotics in the prevention of atopic dermatitis (table 1) awaits future studies.

\section{Treatment of atopic dermatitis}

Once allergic diseases develop, one goal of therapy is to control the patient's clinical symptoms. Probiotics may help to decrease the severity of atopic dermatitis and food allergy. Most clinical studies have targeted pediatric patients (table 2).

In 1997, the first published study in this area [37] examined the effect of Lactobacillus GG in mild atopic eczema in a modest number of infants. After four weeks, SCORAD scores dropped from 26 to 15 , while the control group only changed from 21 to 19 . However, one month after the probiotic was discontinued, both groups had comparable SCORADs. Therefore, in this particular study, the effect of the probiotic was short lived.

The same group of investigators subsequently published two additional studies. One study, published in 2000[38], compared Lactobacillus GG, or Bifidobacterium lactis Bb-1 2 to placebo. After two months SCORAD scores decreased from a baseline of 16 to 1,0 , and 13.4 respectively. However, after 6 months, the median SCORAD was zero (06.6) in all groups, suggesting that the probiotic effect is limited to rapid initiation of improvement in mild disease. The other study underscored the importance of viability [39]. While live probiotic administration resulted in statistically significant improvement of scores, the use of heat-inactivated Lactobacillus GG was associated with adverse gastrointestinal symptoms and further study enrollment was thus halted.

Another study by Kirjavainen et al suggested that Bifidobacterium lactis $\mathrm{Bb} 12$ modifies gut microflora to alleviate early onset atopic eczema[7]. A randomized, but not placebo-controlled study suggested that synbiotics and prebiotics significantly improve atopic dermatitis in older children [40].

Table I: Prevention of sensitization and allergic diseases

\begin{tabular}{|c|c|c|c|c|}
\hline Author & Year & Study type & Probiotic type & Results \\
\hline Abrahamsson & 2007 & $\mathrm{R}, \mathrm{C}, \mathrm{DB}$ & L. reuteri & Decreased lgE-associated eczema \\
\hline Kalliomäki & 2007 & $\mathrm{R}, \mathrm{PC}, \mathrm{DB}$ & LGG & Decreased atopic dermatitis \\
\hline Kukkonen & 2007 & $\mathrm{R}, \mathrm{PC}, \mathrm{DB}$ & $\begin{array}{l}\text { LGG, L. rhamnosus LC705, B. breve Bb99, P. } \\
\text { freudenreichii ssp shermanii JS }\end{array}$ & Lower lgE-associated diseases and eczema \\
\hline Taylor & 2007 & $\mathrm{R}, \mathrm{PC}, \mathrm{DB}$ & L. acidophilus LAVRI- AI & $\begin{array}{l}\text { No change in atopic dermatitis rates or } \\
\text { SCORAD }\end{array}$ \\
\hline Taylor & 2007 & $R, P C, D B$ & L. acidophilus LAVRI- AI & No change in atopic dermatitis \\
\hline Lodinova- Zadnikova & 2004 & C & E. coii & Decreased long-term incidence of allergy \\
\hline Kalliomäki & 2003 & $R, P C, D B$ & LGG & Decreased atopic dermatitis \\
\hline Lodinova- Zadnikova & 2003 & C & E. coii & Decreased allergy development \\
\hline Kalliomäki & 2001 & $R, P C, D B$ & LGG & Decreased atopic dermatatis \\
\hline Rautava & 2001 & $R, P C, D B$ & LGG & Decreased atopic dermatitis \\
\hline
\end{tabular}

$\mathrm{R}=$ randomized, $\mathrm{C}=$ controlled, $\mathrm{PC}=$ placebo-controlled, $\mathrm{DB}=$ double-blinded, $\mathrm{LGG}=$ Lactobacillus $\mathrm{GG}, \mathrm{SCORAD}=$ severity scoring of atopic dermatitis index 
Table 2: Probiotics in treatment of allergies

\begin{tabular}{|c|c|c|c|c|}
\hline Author & Year & Study type & Probiotic type & Results \\
\hline Giovannini & 2007 & $\mathrm{R}, \mathrm{PC}, \mathrm{DB}$ & L. casei DN-II400I & $\begin{array}{l}\text { Longertime free from asthmalrhinitis episodes Less number of episodes } \\
\text { of rhinitis episodes }\end{array}$ \\
\hline Tamura & 2007 & $\mathrm{R}, \mathrm{PC}, \mathrm{DB}$ & L. casei strain shirota & No change in allergic rhinitis \\
\hline Xiao & 2007 & $\mathrm{R}, \mathrm{PC}, \mathrm{DB}$ & B. lon gum BBS36 & Ameliorate Japanese cedar pollinosis \\
\hline Brouwer & 2006 & $R, P C, D B$ & L. rhamnosus I LGG & Lower SCORAD (no different from placebo) \\
\hline Fälster-Holst & 2006 & $\mathrm{R}, \mathrm{PC}, \mathrm{DB}$ & L. rhamnosus GG & Lower SCORAD (no different from placebo) \\
\hline Passeron & 2006 & $\mathrm{R}, \mathrm{PC}, \mathrm{DB}$ & L. rhamonosus Lcr35 and prebiotic & Decreased SCORAD \\
\hline Sistek & 2006 & $R, P C, D B$ & L. rhamnosus, B. lactis & Decreased SCORAD \\
\hline Xiao & 2006 & $\mathrm{R}, \mathrm{PC}, \mathrm{DB}$ & B. longum BBS36 & Ameliorate Japanese cedar pollinosis \\
\hline Xiao & 2006 & $\mathrm{R}, \mathrm{PC}, \mathrm{DB}$ & B. longum BBS36 & Ameliorate Japanese cedar pollinosis \\
\hline Ciprandi & 2005 & $\mathrm{C}$ & Bacillus clausii spores & Decreased nasal symptoms \\
\hline Ishida & 2005 & $R, P C, D B$ & L. acidophil us L-92 & Decreased nasal and ocular symptoms \\
\hline Peng & 2005 & $R, P C, D B$ & L. plantar um 33 & Decreased perennial allergic rhinitis \\
\hline Viljanen & 2005 & $R, P C, D B$ & LGG or MIX & Decreased SCORAD \\
\hline Weston & 2005 & $\mathrm{R}, \mathrm{PC}, \mathrm{DB}$ & L. ferment um & Decreased SCORAD \\
\hline Rosenfeldt & 2004 & $\mathrm{R}, \mathrm{PC}, \mathrm{DB}$ & L. rhamnos us and $L$. re uteri & $\begin{array}{l}\text { Decreased frequency of gastrointestinal symptoms and } \\
\text { lactulose:mannitaol ratio }\end{array}$ \\
\hline Wang & 2004 & $\mathrm{R}, \mathrm{PC}, \mathrm{DB}$ & L. paracasei & Decreased frequency and level of bother of allergic rhinitis \\
\hline Hattori & 2003 & C & B. breve M-I6V & Ameliorate cutaneous and allergic symptoms \\
\hline Kirjavainen & 2003 & $\mathrm{R}, \mathrm{PC}, \mathrm{DB}$ & LGG & Decreased SCORAD \\
\hline Rosenfeldt & 2003 & $R, P C, D B$ & L. rhamnos us and $L$. re uteri & Decreased SCORAD \\
\hline Helin & 2002 & $\mathrm{R}, \mathrm{PC}, \mathrm{DB}$ & LGG & No effect on birch pollen allergy \\
\hline Isolauri & 2000 & $\mathrm{R}, \mathrm{PC}, \mathrm{DB}$ & B. lactis $(\mathrm{Bb}-\mathrm{I} 2)$ or LGG & Decreased SCORAD \\
\hline Majamaa & 1997 & $\mathrm{R}, \mathrm{PC}, \mathrm{DB}$ & LGG & Decreased SCORAD \\
\hline Wheeler & 1997 & $\mathrm{R}, \mathrm{PC}, \mathrm{DB}$ & L. acidophil us & Increased IFN-and less eosinophilia \\
\hline
\end{tabular}

$\mathrm{R}=$ randomized, $\mathrm{C}=$ controlled, $\mathrm{PC}=$ placebo-controlled, $\mathrm{DB}=$ double-blinded, $\mathrm{LGG}=$ Lactobacillus $\mathrm{GG}, \mathrm{SCORAD}=$ severity scoring of atopic dermatitis index

The largest study $(\mathrm{n}=230)$ to date, compared the effects of Lactobacillus GG, a probiotic mix, or placebo[41]. There was no difference between the groups after 4 weeks of therapy, or4 weeks after study supplement was discontinued. However, infants receiving Lactobacillus GG who had specific IgE sensitization had a greater reduction in SCORAD when compared to the placebo group (-26.1 versus $19.8, \mathrm{p}=0.036)$. Furthermore, a reduction of TNF-alpha and an increase in fecal IgA levels were noted [42]. Two other studies demonstrated comparable results. A study 
by Rosenfeldt et al. from Denmark used lyophilized Lactobacillus rhamnosus 19070-2 and Lactobacillus reuteri DSM 122460 ) in older children (average age 5.2 years), and statistically significant improvement in SCORAD was only seen in a subset of children with positive skin prick test and elevated IgE levels [43]. Another study by Sistek et al. showed efficacy of the probiotic Lactobacillus rhamnosus and Bifidobacteria lactis in food-sensitized children[44]. Those three studies taken together reveal that probiotics were not effective for all children with atopic dermatitis but rather in the subset of IgE sensitized children.

However, a study from the Netherlands by Brouwer et al.[45] and another study from Germany by Folster-Holst et al.[46] showed no effect of Lactobacillus rhamnosus or Lactobacillus GG in infants with atopic dermatitis regardless of their IgE sensitization status.

In 2005, Weston et al.[47] from Australia published their experience with using Lactobacillus fermentum VRI-003 PCC for 8 weeks in 53 infants with atopic dermatitis. After 16 weeks the probiotic group had significant reduction of SCORAD scores $(\mathrm{p}=0.03)$ while the placebo group did not $(\mathrm{p}=0.83)$. However, while the change in SCORAD scores from baseline in the probiotic group was significant, the difference between the probiotic and placebo group did not quite reach statistical significance $(\mathrm{p}=0.06)$ by the $16^{\text {th }}$ week.

As pointed out by Passeron and Lacour, in their letter to the editor[48], children receiving placebo treatment in many of these studies significantly improved within a much shorter than expected time. Cellulose and maltose dextran were used as placebo, which could have a prebiotic effect thus explaining the improvement seen in the placebo group. To further examine this effect, the same investigators compared the effects of prebiotics and probiotics (synbiotics) versus prebiotics alone and concluded that both groups had a significant reduction in the SCORAD scores after 3 months[40].

The most recent randomized trial was designed to investigate the therapeutic benefit of Lactobacillus rhamnosus GG (LGG) in infants with atopic dermatitis. Infants 3-12 months of age with mild-to-moderate atopic dermatitis were randomized to receive LGG or placebo as a food supplement for 12 weeks. Fifty-four infants received LGG and 48 infants received placebo. Symptoms improved overtime after 4, 8, and 12 weeks, without any group being statistically different [49].

A recent meta-analysis suggested that probiotics may benefit children and infants with the disorder [50]. The metaanalysis identified ten randomized, controlled trials. A significant overall benefit was demonstrated after the use of probiotics, resulting in a reduction of the dermatitis scores (SCORAD) compared to placebo. Lactobacillus GG appeared to be more effective than other probiotic preparations and children with more severe disease were more likely to benefit from the use of probiotics. Another recent meta-analysis did not show a therapeutic difference among children receiving probiotics [51]. However, this analysis excluded six of the ten studies published, making the validity of the report questionable.

Other studies have examined the effect of probiotic consumption on sensitization to several allergens (e.g. peanut, hen's egg, soy, wheat, milk, cat, dog), as determined by specific IgE production or skin prick test reaction (SPT). The authors could not find a difference before and after the treatment $[22,26,45]$.

Taken together, some of these studies show a slight benefit over placebo for the treatment of atopic dermatitis. However, several of the studies show no benefit.

\section{b) The role of probiotics in Asthma}

A small number of studies exist that try to address the efficacy of probiotic supplementation in the treatment or prevention of asthma. Such studies have heavily focused on the treatment rather than prevention of asthma. Perhaps the largest and the most recent trial was conducted by Giovannini and colleagues using fermented milk containing Lactobacillus casei and studying its effect on the number of episodes of asthma and allergic rhinitis[52]. One hundred and eighty seven children, between two and five years of age, were included in the study. At the end of the twelvemonth trial period the investigators found no statistical difference between intervention and control groups of asthmatic children. However, the number of rhinitis episodes was lower in the probiotic group leading the authors to conclude that Lactobacillus casei may benefit children with allergic rhinitis but not asthmatic children.

One randomized placebo-controlled crossover study examined the effect of yogurt containing $S$. thermophilus and Lactobacillus bulgaricus when given with or without Lactobacillus acidophilus to adolescents and adults with asthma who were sensitized to inhalant allergens. There was no difference in clinical parameters of asthma or laboratory markers of inflammation[53]. One concern with this experimental design arises from the fact that the placebo group received yogurt mixed with bacteria that have probiotic properties. At any rate, neither the active group nor placebo had any improvement in lung function.

The efficacy of probiotics in asthma as a preventive measure has not been evaluated and may be worthwhile studying. However, to date there is no evidence to justify the use of probiotics for treatment or prevention of asthma. 
c) The role of probiotics in Allergic Rhinitis

Reports on the efficacy of probiotics in treating allergic rhinitis are conflicting. Some studies suggest efficacy such as the study by Wang and colleagues, where Lactobacillus paracase $i$-33 was given for 30 days to 80 children with perennial rhinoconjunctivitis. The quality of life questionnaire scores significantly improved relative to placebo[54]. A Japanese study demonstrated that intake of Bifidobacterium lon gum BB536 as a yogurt supplement is effective in relieving symptoms of Japanese cedar pollinosis $[55,56]$. Furthermore, a Finnish study suggested that fermented milk prepared with Lactobacillus gasseri TMC0356 could alter serum IgE concentration through a Th1 immune response in subjects with perennial allergic rhinitis[57]. Others reported that the ingestion of $B$. longum reduced ocular and nasal symptoms as well as need for medication, again in Japanese cedar pollinosis $[55,56,58,59]$. With regard to house dust mite allergy, the use of probiotics resulted in a reduction of symptoms in children and adults with allergic rhinitis [60,61]. In a recent study by Giovannini [52], L. casei DN-1 14001 reduced the number of rhinitis episodes in sixty-four preschool children with allergic rhinitis. Other studies did not show benefit, for example, patients who were allergic to birch pollen and apple food that were treated with $L$. rhamnosus GG during the birch-pollen season, had no reduction of symptom score, nor of sensitization to birch pollen and apple after Lactobacillus rhamnosus supplementation [62] and L. casei strain Shirota did not reduce allergic symptoms of Japanese cedar pollen allergy [63].

\section{Summary}

Probiotics may have a potential role in the prevention and treatment of atopic dermatitis, but studies to date have not been conclusive. Parents should be aware that unequivocal benefit remains to be found. However, the effect can be modest and may depend on the target population. The data addressing the effect of probiotics in allergic rhinitis is even less robust.

Currently, there is no role for probiotic therapy in the treatment of asthma. Future studies will be important to refine the current knowledge base for potential use of probiotics in allergy.

\section{Competing interests}

The author declares that they have no competing interests.

\section{References}

I. Warner JO, et al.: Allergy practice worldwide. a report by the World Allergy Organization Specialty and Training Council. Int Arch Allergy Immunol 2006, 139(2):166-74.

2. Lovasi GS, et al:: Children living in areas with more street trees have lower prevalence of asthma. J Epidemiol Community Health 2008, 62(7):647-9.

3. Romagnani S: Thiand Th2 in human diseases. Clin Immunol Immunopathol 1996, 80(3 Pt I):225-35.
4. Flohr C, Pascoe D, Williams HC: Atopic dermatitis and the 'hygiene hypothesis'. too clean to be true? Br J Dermatol 2005, I52(2):202-16.

5. Ouwehand AC: Antiallergic effects of probiotics. J Nutr 2007, 137(3 Suppl 2):794S-7S.

6. Ogden NS, Bielory L: Probiotics. a complementary approach in the treatment and prevention of pediatric atopic disease. Curr Opin Allergy Clin Immunol 2005, 5(2): 179-84.

7. Kirjavainen PV, et al.: Aberrant composition of gut microbiota of allergic infants. a target of bifidobacterial therapy at weaning? Gut 2002, 51 (1):5I-5.

8. Kirjavainen PV, et al.: Characterizing the composition of intestinal microflora as a prospective treatment target in infant allergic disease. FEMS Immunol Med Microbiol 200I, 32(I): I-7.

9. Bjorksten B: The gastrointestinal flora and the skin--Is there a link? Pediatr Allergy Immunol 200I, I2(Suppi 14):5I-5.

10. Sepp E, et al:: Intestinal microbiota and immunoglobulin E responses in 5-year-old Estonian children. Clin Exp Allergy 2005, 35(9): $1|4|-6$.

II. Voor $\mathrm{T}$, et al.: Atopic sensitization and atopic dermatitis in Estonian and Swedish infants. Clin Exp Allergy 2005, 35(2): I53-9.

12. Bjorksten B, et al.: Allergy development and the intestinal microflora during the first year of life. J Allergy Clin Immunol 2005, 108(4):16-20.

13. Watanabe $S$, et al.: Differences infecalmicroflora between patients with atopic dermatitis and healthy control subjects. J Allergy Clin Immunol 2005, I I I(3):587-9I.

14. Kirjavainen PV, Gibson GR: Healthy gut microflora and allergy. factors influencing development of the microbiota. Ann Med 1999, 3 I (4):288-92.

15. Kalliomaki $M$, Isolauri $E$ : Role of intestinal flora in the development of allergy. Curr Opin Allergy Clin Immunol 2003, 3(I): I5-20.

16. He F, et al.: Comparison of mucosal adhesion and species identification of bifidobacteria isolated from healthy and allergic infants. FEMS Immunol Med Microbiol 200I, 30(I):43-7.

17. Ouwehand $A$, Isolauri $E$, Salminen $S$ : The role of the intestinal microflora for the development of the immune system in early childhood. Eur J Nutr 2002, 4 I (Suppi I):132-7.

18. Penders J, et al.: Molecular finger printing of the intestinal microbiota of infants in whom atopic eczema was or was not developing. Clin Exp Allergy 2006, 36(12):1602-8.

19. Adlerberth I, et al.: Gut microbiota and development of atopic eczema in 3 European birth cohorts. J Allergy Clin Immunol 2007, I 20(2):343-50.

20. (WHO), FaAOFotUNaWHO: Guidelines for the Evaluation of Probiotics in Food. Report of a Joint FAO/WHO Working Group on Drafting Guidelines for the Evaluation of Probiotics in Food. . Accessed on December 7, 2006

21. Winkler P, et al: Molecular and cellular basis of microflorahost interactions. J Nutr 2007, 137 (3 Suppl 2):756S-72S.

22. Flinterman $A E$, et al.: Probiotics have a different immunomodulatory potential in vitro versus ex vivo upon oral administration in children with food allergy. Int Arch Allergy Immunol 2007, 143(3):237-44.

23. Prescott SL, et al.: Clinical effects of probiotics are associated with increased interferon-gamma responses in very young children with atopic dermatitis. Clin Exp Allergy 2005, 35( I 2): 1557-64.

24. Taylor AL, et al:: Effects of probiotic supplementation for the first 6 months of life on allergen-and vaccine-specific immune responses. Clin Exp Allergy 2006, 36(10): 1227-35.

25. Enomoto T, Shimizu K, Shimazu S: [Suppression of allergy development by habitual intake offermented milkfoods, evidence from an epidemiological study]. Arerugi 2006, 55(II): I394-9.

26. Kalliomaki $M$, et al.: Probiotics in primary prevention of atopic disease. a randomised placebo-controlled trial. Lancet 200I, 357(9262): 1076-9.

27. Kalliomaki M, et al.: Probiotics and prevention of atopic disease. 4-yearfollow-up of a randomised placebo-controlled trial. Lancet 2003, 36 I(9372): |869-7|.

28. Kalliomaki M, et al.: Probiotics during the first 7 years of life: a cumulative risk reduction of eczema in a randomized, placebo-controlled trial. J Allergy Clin Immunol 2007, I I 9(4): I01 9-2I.

29. Lodinova-Zadnikova $R$, et al:: [Influence of oral colonization with probiotic $E$. coli strain after birth on frequency of recurrent infections, allergy and development of some immunologic 
parameters. Long-term studies]. Ceska Gynekol 2004, 69(Suppi I):91-7.

30. Lodinova-Zadnikova R, Cukrowska B, Tlaskalova-Hogenova H: Oral administration of probiotic Escherichia coli after birth reduces frequency of allergies and repeated infections later in life (after 10 and 20 years). Int Arch Allergy Immunol 2003, I 3 |(3):209-II.

31. Abrahamsson TR, et al.: Probiotics in prevention of IgE-associated eczema. a double-blind, randomized, placebo-controlled trial. J Allergy Clin Immunol 2007, I I 9(5): I I74-80.

32. Kukkonen K, et al:: Probiotics and prebiotic galacto-oligosaccharides in the prevention of allergic diseases. a randomized, double-blind, placebo-controlled trial. J Allergy Clin Immuno 2007, II (1): 192-8.

33. Taylor AL, et al.: FOXP3 mRNA expression at 6 months of age is higher in infants who develop atopic dermatitis, but is not affected by giving probiotics from birth. Pediatr Allergy Immunol 2007, I 8(I): 10-9.

34. Taylor AL, Dunstan JA, Prescott SL: Probiotic supplementation for the first $\mathbf{6}$ months of life fails to reduce the risk of atopic dermatitis and increases the risk of allergen sensitization in high-risk children. a randomized controlled trial. J Allergy Clin Immunol 2007, I I 9(I): |84-9|

35. Moro G, et al.: A mixture of prebiotic oligosaccharides reduces the incidence of atopic dermatitis during the first six months of age. Arch Dis Child 2006, 9 I (10):8|4-9.

36. Osborn DA, Sinn JK: Probiotics in infants for prevention of allergic disease and food hypersensitivity. Cochrane Database Syst Rev 2007:CD006475.

37. Majamaa H, Isolauri E: Probiotics: a novel approach in the management of food allergy. I Allergy Clin Immunol 1997, 99(2): 179-85.

38. Isolauri $E$, et al:: Probiotics in the management of atopic eczema. Clin Exp Allergy 2000, 30( II):1604-10.

39. Kirjavainen PV, Salminen SJ, Isolauri E: Probiotic bacteria in the management of atopic disease. underscoring the importance of viability. J Pediatr Gastroenterol Nutr 2003, 36(2):223-7.

40. Passeron $T$, et al:: Prebiotics and synbiotics. two promising approaches for the treatment of atopic dermatitis in children above 2 years. Allergy 2006, 61 (4):43I-7.

41. Viljanen M, et al.: Probiotics in the treatment of atopic eczema/ dermatitis syndrome in infants. a double-blind placebo-controlled trial. Allergy 2005, 60(4):494-500.

42. Viljanen $M$, et al.: Probiotic effects onfaecal inflammatory markers and onfaecal IgA in food allergic atopic eczema/dermatitis syndrome infants. Pediatr Allergy Immunol 2005, I6(I):65-7I.

43. Rosenfeldt $\mathrm{V}$, et al.: Effect of probiotic Lactobacillus strains in children with atopic dermatitis. J Allergy Clin Immunol 2003, I I I(2):389-95.

44. Sistek $D$, et al.: Is the effect of probiotics on atopic dermatitis confined to food sensitized children? Clin Exp Allergy 2006, 36(5):629-33

45. Brouwer ML, et al.: No effects of probiotics on atopic dermatitis in infancy. a randomized placebo-controlled trial. Clin Exp Allergy 2006, 36(7):899-906.

46. Folster-Holst R, et al:: Prospective, randomized controlled trial on Lactobacillus rhamnosus in infants with moderate to severe atopic dermatitis. Br J Dermatol 2006, I55(6): |256-6I.

47. Weston $S$, et al: Effects of probiotics on atopic dermatitis. a randomised controlled trial. Arch Dis Child 2005, 90(9):892-7.

48. Passeron T, Lacour J: Effects of Probiotics on Atopic Dermatitis. Arch Dis Child 2005, 20(4): 17I-176.

49. Gruber $C$, et al: Randomized, placebo-controlled trial of Lactobacillus rhamnosus GG as treatment of atopic dermatitis in infancy. Allergy 2007, 62(II): 1270-6.

50. Michail S, Onady G, Stolfi A, Johnson T: Efficacy of probiotics in treatment ofpediatric atopic dermatitis a meta-analysis of randomized, controlled trials. 2008, $101(5): 508-16$.

5I. Lee J, Seto D, Bielory L: Meta-analysis of clinical trials of probiotics for prevention and treatment of pediatric atopic dermatitis. J Allergy Clin Immunol 2008, I 2I(I): I I6-I2I.

52. Giovannini M, et al.: A randomized prospective double blind controlled trial on effects of longterm consumption offermented milk containing Lactobacillus casei in pre-schoo children with allergic asthma and/or rhinitis. Pediatr Res 2007 , 62(2):215-20.

53. Wheeler JG, et al.: Immune and clinical impact of Lactobacillus acidophilus on asthma. Ann Allergy Asthma Immunol 1997, 79(3):229-33

54. Wang MF, et al.: Treatment of perennial allergic rhinitis with lactic acid bacteria. Pediatr Allergy Immunol 2004, I 5(2): I 52-8.

55. Xiao JZ, et al.: Probiotics in the treatment of Japanese cedar pollinosis: a double-blind placebo-controlled trial. Clin Exp Allergy 2006, 36(I I): I425-35

56. Xiao JZ, et al:: Effect of probiotic Bifidobacterium longum BB536 [corrected] in relieving clinical symptoms and modulating plasma cytokine levels of Japanese cedar pollinosis during the pollen season. A randomized double-blind, placebo-controlled trial. J Investig Allergol Clin Immunol 2006, 16(2):86-93.

57. Morita $\mathrm{H}$, et al.: Preliminary human study for possible alteration of serum immunoglobulin $E$ production in perennial allergic rhinitis with fermented milk prepared with Lactobacillus gasseri TMCO356. Microbiol Immunol 2006, 50(9):70I-6.

58. Xiao JZ, et al.: Changes in plasma TARC levels during Japanese cedar pollen season and relationships with symptom development. Int Arch Allergy Immunol 2007, I 44(2): I 23-7.

59. Xiao JZ, et al: Clinical efficacy of probiotic Bifidobacterium longum for the treatment of symptoms of Japanese cedar pollen allergy in subjects evaluated in an environmental exposure unit. Allergol Tnt 2007, 56(I):67-75.

60. Tshida $Y$, et al.: Clinical effects of Lactobacillus acidophilus strain L-92 on perennial allergic rhinitis: a double-blind, placebo-controlled study. J Dairy Sci 2005, 88(2):527-33.

61. Peng GC, Hsu CH: The efficacy and safety of heat-killed Lactobacillus paracasei for treatment of perennial allergic rhinitis induced by house-dust mite. Pediatr Allergy Tmmunol 2005, 16(5):433-8.

62. Helin T, Haahtela S, Haahtela T: No effect of oral treatment with an intestinal bacterial strain, Lactobacillus rhamnosus (ATCC 53I03), on birch-pollen allergy: a placebo-controlled double-blind study. Allergy 2002, 57(3):243-6.

63. Tamura $M$, et al.: Effects of probiotics on allergic rhinitis induced by Japanese cedar pollen: randomized double-blind, placebo-controlled clinical trial. Tht Arch Allergy Tmmunol 2007, 143(I):75-82.

Publish with Bio Med Central and every scientist can read your work free of charge

"BioMed Central will be the most significant development for disseminating the results of biomedical research in our lifetime. "

Sir Paul Nurse, Cancer Research UK

Your research papers will be:

- available free of charge to the entire biomedical community

- peer reviewed and published immediately upon acceptance

- cited in PubMed and archived on PubMed Central

- yours - you keep the copyright 